Article

\title{
Sustainable Development for Small Economy and Diversification from a Dominant Industry: Evidence from Macao
}

\author{
Fei Choi ${ }^{1}$, Chi Tin Hon ${ }^{2}$ (D), Yan Hua Mao ${ }^{3, *}$ and Ivan Ka Wai Lai ${ }^{4, *(D)}$ \\ 1 School of Business, Sun Yat-sen University, No. 135, Xingang Xi Road, Guangzhou 510275, China; \\ fayechoi129@hotmail.com \\ 2 Macau Institute of Systems Engineering, Macau University of Science and Technology, Avenida Wai Long, \\ Taipa, Macau, China; cthon@must.edu.mo \\ 3 The Center for Studies of Hong Kong, Macao and Pearl River Delta, Institute of Guangdong, Hong Kong and \\ Macao Development Studies, Sun Yat-sen University, No. 135, Xingang Xi Road, Guangzhou 510275, China \\ 4 Faculty of International Tourism and Management, City University of Macau, Avenida Padre Tomás Pereira, \\ Taipa 999078, Macau, China \\ * Correspondence: mnsmyh@mail.sysu.edu.cn (Y.H.M.); ivanlai@cityu.mo (I.K.W.L.)
}

Received: 26 January 2019; Accepted: 12 March 2019; Published: 18 March 2019

check for updates

\begin{abstract}
While the Macao gambling industry has developed prosperously, its rapid development raises a problem of economic dependence on gambling that restricts economic diversification and causes a sustainable issue of non-gambling industries. In recent years, regulating and controlling the appropriate scale of the gambling industry have been regarded as a solution for sustainable economic development. Consequently, it is quite important to give a quantitative scale to the future development of the gambling industry. This study aims to estimate the appropriate scale of the gambling industry under the expectation of the optimal development of moderate economic diversification in Macao. This study employs the method of Measuring Economic Diversification in Hawaii in 2011 to evaluate the levels of diversification of Macao's economy. A Data Envelopment Analysis (DEA) efficiency calculated by a bootstrapping model is applied to obtain the operational efficiency of Macao's gambling industry. A transition probability matrix in three scenarios is predicted by expert interviews and industry interviews. The appropriate scale of Macao's gambling industry until 2021 is forecasted by Markov chain. The predicted result shows that the growth rate of gambling will not exceed $3 \%$ in terms of achieving the goal of optimal developing moderate economic diversification in Macao.
\end{abstract}

Keywords: sustainability; gambling industry; economic diversification; dominant industry; Macao

\section{Introduction}

As a leading gambling destination, in 2017, Macao attracted more than 30 million tourists and created the highest gambling revenue (33 billion US dollars) in the world [1]. The development of Macao's gambling industry is the result of its history, economic development, resource limitations and preferential policy [2]. Although these factors helped Macao to obtain a competitive advantage in gambling tourism, this typical small economy raises a problem-economic dependence on gambling restricts economic diversification. The gambling industry increases labor wages and provides good treatment, which results in its strong absorption of economic resources. However, faster growth of gambling industry leads to higher income inequality [3] which limits other industries' survival and development. Scholars contend that a low level of diversification or concentrated economy can dramatically react to external influences, such as changes in demand for one product $[4,5]$ and a 
diversified regional economy is less responsive to fluctuations to extra-regional economic growth [6]. Since diversification can reduce a nation's economic volatility and increase its real activity performance, so having a diverse economy has long been thought to play a key role in a sustainable economy [5]. Therefore, both the Macao government [7-10] and scholars [11-14] have recognized the importance of economic diversification, which is the source of long-term economic growth $[5,15,16]$. Moderate diversification of the economic structure is a way to drive economic sustainability in Macao. Thus, it is critical to establish moderate economic diversification in Macao.

To establish a moderate economic structure, the Macao government is facilitating the development of other industries, such as Meetings, Incentives, Conferences and Exhibitions (MICE), Traditional Chinese Medicines (TCM), Cultural and Creative Industries (CCI) and featured financial services. The Macao government also announced its policy spindle for gambling industry development, "adjustment of the appropriate scale of gambling industry" [7,9]. Recently, some researchers have studied the sources of threats and challenges to Macao's economic development [11,17], the ways Macao's economy is developing and diversifying $[11,13,14,17,18]$ and sustainable tourism development in Macao [12]. They supported the development of moderate economic diversification and agreed that by controlling the scale of the gambling industry, more resources could be unlocked and reallocated to non-gambling industries [19]. However, some academics advocate the advantages of cluster economies or agglomeration economies [20-22], which have the advantages of sharing common resources (i.e., technology and labor), lower unit costs and better innovations for increasing returns to scale and enhancing the growth opportunities of other industries and clusters [20-22]. In a recent study, Aratuo and Etienne [23] studied the relationship between economic growth and tourism-related industries in the US in 1998-2017. They found that tourism-related industries providing local offerings drive the performance of other industries. Although most of the research on agglomeration economies and cluster economies consider the agglomeration of manufacturing industries [24,25], the agglomeration of service industries may occur if they can benefit from the concentration of customers [25]. Therefore, Macao's gambling industry tends to concentrate in certain areas in Macao instead of being scattered across Macao. Considering the needs for supporting service industries such as banks and other financial intermediaries, restaurants, tourism and other business services, the agglomeration of casinos can derive similar benefits to the agglomeration of manufacturing industries, especially regarding the enhancement of the growth opportunities of other industries and clusters [22]. In other words, the agglomeration of casinos may lead to the growth of other industries and clusters. This implies that over-adjustment of the gambling industry may harm the development of moderate economic diversification in Macao. Thus, how to strike a balance between moderate economic diversification and further development of the gambling industry must be determined.

The concept of appropriate scale comes from the economies of scale. Appropriate extension or reduction of the production scale will make the distribution of production factors, like land, capital and labor, more reasonable and will achieve optimal management efficiency under existing conditions [26,27]. To adjust the scale of the gambling industry appropriately, we should know how to calculate this 'appropriate scale.' In general, if the scale of the gambling industry is higher than this 'appropriate scale,' it will limit the development of moderate economic diversification. Then, it causes the sustainable issue of non-gambling industries. On the other hand, if the scale of the gambling industry is lower than this 'appropriate scale,' it will also reduce its support of non-gambling industries to achieve a moderate and diversified economy. It causes the sustainable issue for both gambling and non-gambling industries. Therefore, our study relates the appropriate scale of the gambling industry not only in terms of the economic efficiency of this industry but also the overall economic diversification in Macao. This study helps to address the paradox between economic growth of the gambling industry and sustainable growth of non-gambling industries.

To contribute to a solution for sustainable economic development in Macao, this study aims to determine the appropriate scale of the gambling industry for optimal development of moderate economic diversification in Macao. Firstly, this study applies an entropy index of economic 
diversification [28] to measure the levels of diversification of Macao's economy from 2008-2016. Then, a Data Envelopment Analysis (DEA) [29-31] is used to measure the efficiency of the gambling industry. A transition probability matrix for three scenarios (rapid, stable and slow transitions) is developed based on expert interviews. To evaluate the appropriate scale, a Markov chain [32] is applied to forecast the future scale of the non-gambling industry and the gambling industry until 2021. The results of this study can be applied to other gambling destinations (such as Cambodia) that may soon face a similar sustainable economic problem of a concentration in the gambling industry and may want to promote industrial diversification. For sustainable economic growth caused by technological innovation and human capital accumulation, it is essential to transform and upgrade the industrial structure. This study also contributes to sustainability through the understanding of the transformation of the industrial structure and its relationship with sustainable economic growth.

\section{Literature Review}

\subsection{Economic Diversification}

The economy with a dominant industry is destined to create unsustainable economic development. The decline of Detroit's economy because of its over-reliance on the automotive industry is an example. Therefore, scholars have proposed the need for economic diversification, a strategy to transform an economy from relying on a single source to having multiple sources of monetary income spread over primary, secondary and tertiary industries [16]. Conceptually, Nourse [6] and Hackbert and Anderson [4] stated that economic diversification can build resilience against fluctuations in extra-regional economic activity and reduce dramatic reactions to external influence, such as changes in demand for one product. Empirically, measures of economic diversification include entropy measures [4,33], portfolio variance measure [34] and the Ogive index [35]. As a test of such measures, higher industrial diversification, as measured by entropy measures and the portfolio variance measure, was shown to lead to lower economic instability using samples of US [33,34].

International bodies, for example, the International Monetary Fund and United Nations, have committed to promoting economic diversification for sustainable economic development in resource-rich countries (i.e., countries within the Gulf Cooperation Council) $[15,36]$ and Asian Landlocked Developing Countries [37] to reduce their economic volatility. However, since Macao is neither a resource-rich region nor a landlocked region, its case for moderate economic diversification will be a good example.

\subsection{Moderate Economic Diversification and Sustainable Development in Macao}

Macao's economic development has been dominated by the gambling industry. First, is manifested in its proportion of GDP. After the end of the monopoly system of the gambling industry in 2002, the proportion of GDP attributable to the gaming industry increased from $40.9 \%$ in 2006 to $63 \%$ in 2011. Although the proportion of GDP decreased from 63\% in 2011 to $47.2 \%$ in 2016, the gambling industry still dominated a large percentage of Macao's economy [8]. The dominant industry raises a threat to Macao's economy [11]. Second, since labor is a key determinant of tourism efficiency and productivity [38], the gambling industry of Macao employs the largest percentage of the working population. From 2007 to 2016, the gambling industry employed about $23 \%$ to $26 \%$ of the working population [8]. Such a domination in gambling makes Macao vulnerable to a decline in the demand for gambling, which may arise from competing destinations such as Phnom Penh in Cambodia, Singapore and Japan, community alienation, slower growth of China's economy and Chinese government policies [11]. The decline in gambling demand in 2015 and 2016 following a crackdown by the Chinese government on corruption involving junket operators contributed to a corresponding plunge in Macao's GDP [8]. This situation makes economic diversification and sustainable development of Macao a vital issue. 
Apart from economic volatility, negative externalities, for example, inflation, the rise of rental and property prices, increases in the cost of living, traffic problems, an increase in criminal cases and gambling-related crimes were identified by Macao's citizens [39-41]. Because of the high volume of tourists, as measured by the Tourism Intensity Index and negative externalities, there may be increasing negative aspects of resident-tourist relations that detrimentally affect the gambling and tourism industries [42]. This makes sustainable development in Macao less viable.

Considering the disadvantages of the heavy reliance on the gambling industry for economic development, the Macao government has realized the need for moderate economic diversification and is currently facilitating the development of other industries such as MICE, Traditional Chinese Medicine, Cultural and Creative Industries and featured financial services.

\subsection{Agglomeration Economies}

Agglomeration economies are the benefits that arise when firms and people are located near one another in cities and industrial clusters [43]. Marshall [44] pioneered this concept, suggesting that the benefits of agglomeration economies include labor market pooling, the sharing of inputs and knowledge spill-overs. Scholars after Marshall continued to conduct research on agglomeration economies. While most of the studies have focused on manufacturing industries [24,25], the benefits of agglomeration economies are similar across industries. They include the sharing of common resources (i.e., technology and labor), lower unit costs, better innovations for increasing returns to scale, proximity to suppliers and customers, knowledge spill-overs, enhancement of the strength of related clusters and the creation of new industries if there is a strong regional cluster [20-22,24,25,45].

The source of agglomeration is different between manufacturing industries and service industries [25]. The source of manufacturing industry agglomeration is the proximity to and concentration of supporting industries, while the source of service agglomeration is the proximity to and concentration of customers [25].

\subsection{The Dilemma of Moderate Economic Diversification, Agglomeration Economies of Gambling Industry and Diminishing Returns in Macao}

Because of its high concentration of casinos, Macao's economy is enjoying the benefits of agglomeration economies suggested by scholars in studies of other contexts. They include the concentration of customers, skilled labor and knowledge spill-over [25,45] and increase the strength of related agglomeration in the region [22]. The benefit of agglomeration economies suggests that over-adjustment of the gambling industry may harm the development of moderate economic diversification in Macao.

Apart from a concern about over-adjustment, the diminishing returns of the gambling industry in Macao may also be a concern. Delgado et al. [22] stated that "narrow regional specialization in an industry is likely to result in diminishing returns and the presence of unrelated economic activity is unlikely to significantly enhance opportunities for growth but may increase congestion." Applied to the context of Macao, the gambling industry may eventually lead to diminishing returns. Delgado et al.'s [22] findings imply that the development of the gambling industry in Macao may eventually reach a point of diminishing returns to scale, suggesting that the determination of an appropriate scale for gambling industry development is pertinent. The determination of an appropriate scale should strike a balance between the seemingly contradictory themes of continuous development without over-adjustment in the gambling industry and diminishing returns of that industry.

\section{Research Methods}

This study incorporated four steps: First, this study applied an entropy index of economic diversification to determine the levels of diversification of Macao economy. Second, the study adopted DEA to calculate the efficiency by a bootstrapping model to understand the efficiency of Macao's gambling industry. Third, the study derives the transition probability matrix of the three scenarios 
through interviews with native economic experts and the senior executives of large-scale gambling companies. Last, this paper employed the Markov chain to forecast the appropriate scale for Macao's gambling industry. This section introduces measuring methods, data source and chosen indicators.

\subsection{Entropy Index of Economic Diversification}

The measurement of diversification of Macao's economy is related to the measurement of the diversification of its industrial structure. Industrial structure refers to the constitution of each industry and the proportion of its added value in an economy. The industrial added value can be generally calculated by the producer's price (including product tax) and the basic price (not including the product tax). The franchise tax (part of product tax) of Macao's gambling industry should be considered part of the industrial total added value, because it is deducted from industrial total revenue or total turnover, generated from industrial economic activities that are not levied by extra ways and is regarded as a part of the output. Meanwhile, the gambling industry plays a leading role in Macao's economy and makes huge tax contributions, so calculating the gambling tax as an industrial output can more accurately reflect the proportion of the gambling industry in Macao's overall economic structure. From the viewpoint of appropriate diversification of Macao's economy development, the GDP calculated by the producer's price has a higher reference value than if it is calculated by the basic price in the input-output analysis. Thus, this study applied the industrial total added value (by producer's price) by chain price to calculate the entropy index of economic diversification.

The Entropy Index of Diversification (EID) [28] is one of the indicators that measures economic diversification in academia. Its calculation equation is

$$
E D I=\sum_{i=1}^{N} S_{i} \ln \left(\frac{1}{S_{i}}\right)
$$

In Equation (1), $N$ is the number of industries; $S_{i}$ is the proportion of added value of the $i$ th industry of the total added value; and $l n$ is the natural logarithm. If all added value is concentrated on one industry, the score of the entropy index is 0 ; with an increasing number of industries, the maximum score is $\ln (N)$. Thus, a larger entropy index score refers to a higher level of economic diversification, while the smaller score reflects a relatively high level of economic concentration.

\subsection{Data Envelopment Analysis (DEA)}

This study applied the Data Envelopment Analysis (DEA) to measure the efficiency of Macao's gambling industry. DEA is a nonparametric frontier efficiency analysis that measures the production efficiency of the Decision-Making Unit (DMU). This model is applied to evaluate DMU's technology efficiency (TE) under the condition of constant returns to scale (CRS). Its basic premise is to assume that there are $K$ DMUs including $L$ input indicators and $M$ output indicators that need to be evaluated. Then, the equation of the $i$ th $(i=1,2, \ldots, K)$ DMU's DEA model is

$$
\begin{gathered}
\min \left(\theta-\varepsilon\left(e_{1}^{T} s^{-}+e_{2}^{T} s^{+}\right)\right) ; \\
\text {s.t. } \sum_{i=1}^{k} x_{i l} \lambda_{i}+s^{-}=\theta x_{l}^{n}, l=1,2 \ldots, L ; n=1,2 \ldots, K \\
\sum_{i=1}^{k} y_{i m} \lambda_{i}-s^{+}=y_{m}^{n}, m=1,2 \ldots, m ; \lambda_{i} \geq 0 . i=1,2 \ldots, K .
\end{gathered}
$$

In Equation (2), $\theta$ is the TE value, $0 \leq \theta \leq 1 ; \varepsilon$ is a dimensionless variable; $\mathrm{s}^{-}$and $\mathrm{s}^{+}$values $\geq 0$ are slack variables; $e_{1}^{T}$ is an $m$ dimension unit vector; $e_{2}^{T}$ is a $k$ dimension unit vector; $\lambda \mathrm{i} \geq 0$ is the weighted variable; $x_{\mathrm{il}}$ is the $l$ th $(l=1,2, \ldots, L)$ recourse input of the $i$ th DMU; and $y_{\mathrm{im}}$ is the $m$ th $(m=1,2, \ldots, M)$ output of the $i$ th DMU. When production technology is considered under the condition of variable 
returns to scale (VRS), the constraint condition $\sum_{i=1}^{n} \lambda_{i}=1$ is introduced into Equation (2) to get the DEA-BCC model (proposed by Banker, Charnes and Cooper) [29].

In conclusion, the DEA method fits the condition of more input and more output and does not need to set the functional forms of input variables and output variables. However, a study conducted by Simar and Wilson [46] revealed that both estimator $\hat{\theta}_{C C R}$ calculated by the CCR model (proposed by Charnes, Cooper and Rhodes) [47] and estimator $\hat{\theta}_{B B C}$ calculated by the BCC model are consistent under scenario of constant returns to scale (CRS). However, $\hat{\theta}_{B B C}$ has consistency while $\hat{\theta}_{C C R}$ does not under the scenario of variable returns to scale (VRS), which results in errors of calculation and goes against practical research. In view of this, studies by Zhang [48] and Yuan et al. [49] revealed that Macao gambling industry does not have constant returns to scale (CRS) and thus, this study only applied the DEA-BCC method and bootstrap method. In the following text, we describe the use of a bootstrapping-DEA model to attach more importance to the efficiency of Macao gambling industry as compared with a traditional DEA-BCC method to reveal its advantages or disadvantages.

The basic concept of the bootstrap method is obtaining a known sample $\theta_{0}=\left(\theta_{1}, \theta_{2}, \ldots, \theta_{K}\right)$ from an unknown ensemble of probability distribution $f$ by random sampling and then using a sample parameter $\hat{\boldsymbol{\varphi}}=\varphi\left(\theta_{0}\right)$ obtained from sample $\theta_{0}$ to estimate the ensemble parameter $\varphi=\varphi(f)$. If the probability distribution of sample parameter $\hat{\varphi}$ is unknown, it is necessary to use an empirical density function with a sample parameter simulated by bootstrap repeated sampling to judge the error between ensemble parameter $\varphi$ and sample parameter $\hat{\varphi}$. Based on the premise of bootstrap, steps of bootstrapping-DEA are as follows:

Step 1: Based on each DMU's input-output set $\left(X_{i}, Y_{i}\right), i=1,2, \ldots, K$, get the initial efficiency score $\hat{\boldsymbol{\theta}}_{i}$, consisting of a set $\hat{\boldsymbol{\theta}}_{\mathbf{0}}=\left(\hat{\boldsymbol{\theta}}_{1}, \hat{\boldsymbol{\theta}}_{2}, \ldots, \hat{\boldsymbol{\theta}}_{K}\right)$ of efficiency scores of all Decision Making Units;

Step 2: Apply the smoothing bootstrap method to get a bootstrap sample $\boldsymbol{\theta}_{\mathbf{1}}^{*}=\left(\boldsymbol{\theta}_{\mathbf{1}}^{*}, \boldsymbol{\theta}_{2 b^{\prime}}^{*}, \ldots, \boldsymbol{\theta}_{\mathbf{K} b}^{*}\right)$ by repeated sampling from the efficiency score sample $\hat{\boldsymbol{\theta}}_{0}=\left(\hat{\boldsymbol{\theta}}_{1}, \hat{\boldsymbol{\theta}}_{2}, \ldots, \hat{\boldsymbol{\theta}}_{K}\right) ; b$ refers to $b$ iterations by using the bootstrap method;

Step 3: Based on the smoothing bootstrap efficiency set $\theta_{b}^{*}=\left(\theta_{1 b^{\prime}}^{*}, \boldsymbol{\theta}_{2 b^{*}}^{*}, \ldots, \boldsymbol{\theta}_{K \boldsymbol{k}}^{*}\right)$ estimated by Step 2 and under conditions of constant output, adjust the initial input variable $X_{\mathrm{i}}$ and then get $\boldsymbol{X}_{i b}^{*}=\left(\hat{\boldsymbol{\theta}}_{i}^{\prime}, \boldsymbol{\theta}_{i b}^{*}\right) \times X_{i}, i=1,2, \ldots, K$;

Step 4: Based on the adjusted input-output amount $\left(X_{i b}^{*}, Y_{i}\right), i=1,2, \ldots, K$, use the DEA method to compute each DMU's efficiency score $\boldsymbol{\theta}_{1 b}^{*}$ again;

Step 5: Repeat Steps 2 to $4 \mathrm{~B}$ times and then get a series of efficiency scores $\boldsymbol{\theta}_{1 b^{\prime}}^{*} b=1,2, \ldots, B$;

Step 6: Compute the error $\overline{\mathbf{B i a s}}\left(\hat{\boldsymbol{\theta}}_{i}\right)$ of the initial efficiency score $\hat{\boldsymbol{\theta}}_{i}$ of each DMU and the adjusted efficiency score $\widetilde{\boldsymbol{\theta}}_{i}$ after error correcting:

$$
\begin{gathered}
\overline{\operatorname{Bias}}\left(\hat{\theta}_{i}\right)=\boldsymbol{B}^{-1} \sum_{\mathrm{b}=1}^{\mathrm{B}}\left(\hat{\theta}_{i b}^{*}\right)-\hat{\theta}_{i} \\
\widetilde{\boldsymbol{\theta}}_{\boldsymbol{i}}=\hat{\boldsymbol{\theta}}_{\boldsymbol{i}}-\overline{\operatorname{Bias}}\left(\hat{\boldsymbol{\theta}}_{\boldsymbol{i}}\right)=2 \hat{\boldsymbol{\theta}}_{\boldsymbol{i}}-B^{-1} \sum_{\mathrm{b}=1}^{\mathrm{B}}\left(\hat{\theta}_{i b}^{*}\right)
\end{gathered}
$$

Step 7: Calculate the confidence interval of the adjusted efficiency score $\widetilde{\theta}_{i}$ after error correcting the confidence level $\alpha$. The confidence interval of the adjusted efficiency score $\widetilde{\theta}_{i}$ after error correcting is $P_{r}\left(-\hat{b}_{\alpha} \leq \hat{\boldsymbol{\theta}}_{i b}^{*}-\hat{\theta}_{i} \leq-\hat{a}_{\alpha}\right)=1-\alpha$ and furthermore, we have $\hat{\theta}_{i}+\hat{a}_{\alpha} \leq \widetilde{\theta}_{i} \leq \hat{\theta}+\hat{b}_{\alpha}$.

The bootstrapping-DEA model can avoid issues like having a small-sized sample, sample sensitivity and outliers, rectify the offsetting of the efficiency score and make up for the shortcomings of the traditional DEA method. The small economy size and incomplete economic industry in Macao result from difficulty getting relevant data. The bootstrapping-DEA model can solve the problem of having insufficient samples by repeated sampling so that the actual efficiency and future development tendency can be better analyzed. 


\subsection{Markov Chain Forecast}

The Markov chain, a widely used random process model, involves the quantitative analysis of a system's status transformation that can be transferred with time and has the property of probability, which allows it to consider the influences of previous events on later events. The Markov chain forecast method predicts laws of development of systematic dynamic data in the light of probability of status transformation and fits issues to a forecast with big random fluctuations but requires the objects being forecasted to have the characteristics of a Markov chain as well as being a mean value-like stable process. A Markov chain forecast has to establish a systematic status transition probability matrix, which can be estimated by a market survey, expert interview and regression model. Let us respectively assume that $x_{2}, \ldots x_{n}$ and $E=\{1,2, \ldots, m\}$ are a series of index sequence values of the Markov chain and the status space of the Markov chain.

Let us compute the distribution vector in the initial status to form the state vector and then calculate sequential values of the indicator through a transition matrix step, using $f_{i j}$ to refer to times when status $i$ transfer to status $j, i, j \in E$. In practical applications, only one step transition probability matrix is considered. Matrix $\left(f_{i, j}\right)_{i, j \in E}$, constituted by $f_{i j}(i, j \in E)$, is named the status transition probability matrix. The transition probability is the value that divides every matrix element by the sum of each row it is in and can be referred to as $P_{i j}(i, j \in E)$. The equation is

$$
P_{i j}=\frac{f_{i j}}{\sum_{j=1}^{m} f_{i j}} .
$$

A Markov chain model is used to forecast, while $\chi^{2}$ can be used to test whether the random variable sequence of the system has the Markov property. The times that the sequential value of indicator transfers from status $i$ to status $j$ through a one-step transition matrix can be referred to as $f_{i j}$, $i, j \in E$ and then we can get the system's marginal probability, the equation of which is

$$
P_{j}=\frac{\sum_{i=1}^{m} f_{i j}}{\sum_{i=1}^{m} \sum_{j=1}^{m} f_{i j}} .
$$

It is the sum of elements in the $j$ th column divided by the sum of all elements in the state transition frequency matrix. When $n$ is large enough, $x^{2}=2 \sum_{i=1}^{m} \sum_{j=1}^{m} f_{i j}=\left|\log \frac{p_{I I}}{p_{J}}\right|$ obeys the distribution of $x^{2}$ at the free degree of $(m-1)^{2}$. If the $x^{2}$ value is larger than the value of $x_{\alpha}^{2}(m-1)^{2}$, the sequence has the Markov property. Otherwise the sequence cannot be forecast by the Markov chain.

Forecasting the development tendency of Macao's gambling industry by applying the Markov chain and researching features of Macao's industrial structure has strong practical significance. Since the Markov chain forecasting method has significant support for short-term research and relatively strong sensitivity to short-term change, this method was chosen to forecast changes in Macao's industrial diversification.

\subsection{Data Collection and Variables Description}

This study calculated the entropy index of economic diversification based on the chain volume measures (2015) of total added value (producer price) of 16 industries in Macao from 2008 to 2016. Relevant data are from the Statistics and Census Service of the Government of Macao Special Administrative Region.

This study calculated the DEA efficiency of the gambling industry in Macao from 2008 to 2016, setting years as the Decision-Making Units (DMU) and adopting DEA efficiency calculated by a bootstrapping model to discover the change of efficiency of the gambling industry in Macao. In this study, input variables are the numbers of casinos (order of magnitude is 1), gambling tables (order of magnitude is 1), hotel rooms (order of magnitude is ten thousand) and employees (order of magnitude is ten thousand). These input variables reflect the scale of the gambling industry. 
To be specific, the number of casinos, amount of gambling tables, number of hotel rooms and the number of employees reflect land, capital and human investments. As a small economy, land, capital and human resources are the main inputs of Macao economic development. Output variables include the gambling gross income (order of magnitude is 100 million MOP), the gambling tax revenue (order of magnitude is 100 million MOP) and the GDP (order of magnitude is 100 million MOP). The gambling gross income and gambling tax revenue are good measurements of the gambling industry's outcome. Since gambling tax revenue accounts for a high proportion of Macao GDP, GDP is also used as a measurement of the gambling industry's outcome.

\section{Results}

\subsection{Entropy Index of Economic Diversification}

This study calculated the entropy index of economic diversification based on the chain volume measures of the total added value (producer price) of 16 industries in Macao in 2015. Table 1 and Figure 1 illustrate the results of the revealed relevant calculation.

Table 1. Macao entropy index of economic diversification.

\begin{tabular}{cccccccccc}
\hline Year & 2008 & 2009 & $\mathbf{2 0 1 0}$ & $\mathbf{2 0 1 1}$ & $\mathbf{2 0 1 2}$ & $\mathbf{2 0 1 3}$ & $\mathbf{2 0 1 4}$ & $\mathbf{2 0 1 5}$ & 2016 \\
\hline $\begin{array}{c}\text { Entropy index of } \\
\text { economic diversification }\end{array}$ & 2.04 & 1.99 & 1.74 & 1.60 & 1.60 & 1.58 & 1.68 & 1.97 & 2.02 \\
\hline
\end{tabular}

Comment: results were calculated by the chain price (2015) of the main industries' total added value (producer's price). Data source: Statistics and Census Service of the Government of Macao Special Administrative Region.

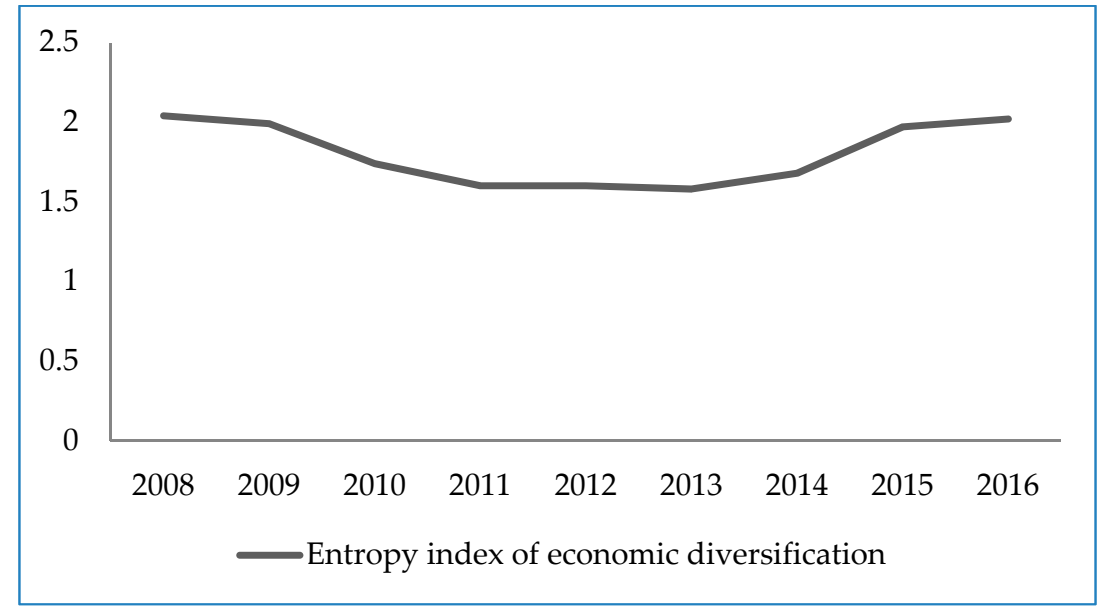

Figure 1. Macao entropy index of economic diversification.

According to the results, Macao's industrial diversification continuously decreased from 2008 to 2013, while Macao's gambling industry developed rapidly after it opened. However, it started to change in 2014. In 2015, the gross income of the gambling industry had declined by $34.3 \%$, which resulted in a rise in the entropy index of economic diversification calculated by the industrial added value. Therefore, once industrial concentration shows a slight decline, the industrial structure is more diversified.

\subsection{Bootstrapping-DEA Efficiency}

To understand Macao's gambling industry's efficiency, the efficiency of bootstrapping-DEA based on variable returns to scale (VRS) was calculated. Table 2 demonstrates the results of bootstrapping-DEA efficiency. Figure 2 illustrates the gambling industry's efficiency along with the economic diversification in Macao from 2008-2016. 
Table 2. Gambling industry's efficiency and economic diversification in Macao.

\begin{tabular}{cccc}
\hline Year & DEA-BCC Efficiency & $\begin{array}{c}\text { Bootstrapping-DEA } \\
\text { Efficiency }\end{array}$ & $\begin{array}{c}\text { Entropy Index of Economic } \\
\text { Diversification }\end{array}$ \\
\hline 2008 & 0.68648 & 0.60396 & 2.04 \\
2009 & 0.61839 & 0.56198 & 1.99 \\
2010 & 0.82248 & 0.73357 & 1.74 \\
2011 & 0.99921 & 0.92339 & 1.60 \\
2012 & 0.91766 & 0.89850 & 1.60 \\
2013 & 1.00000 & 1.00000 & 1.58 \\
2014 & 1.00000 & 1.00000 & 1.68 \\
2015 & 0.81936 & 0.81762 & 1.97 \\
2016 & 0.83262 & 0.83097 & 2.02 \\
\hline
\end{tabular}

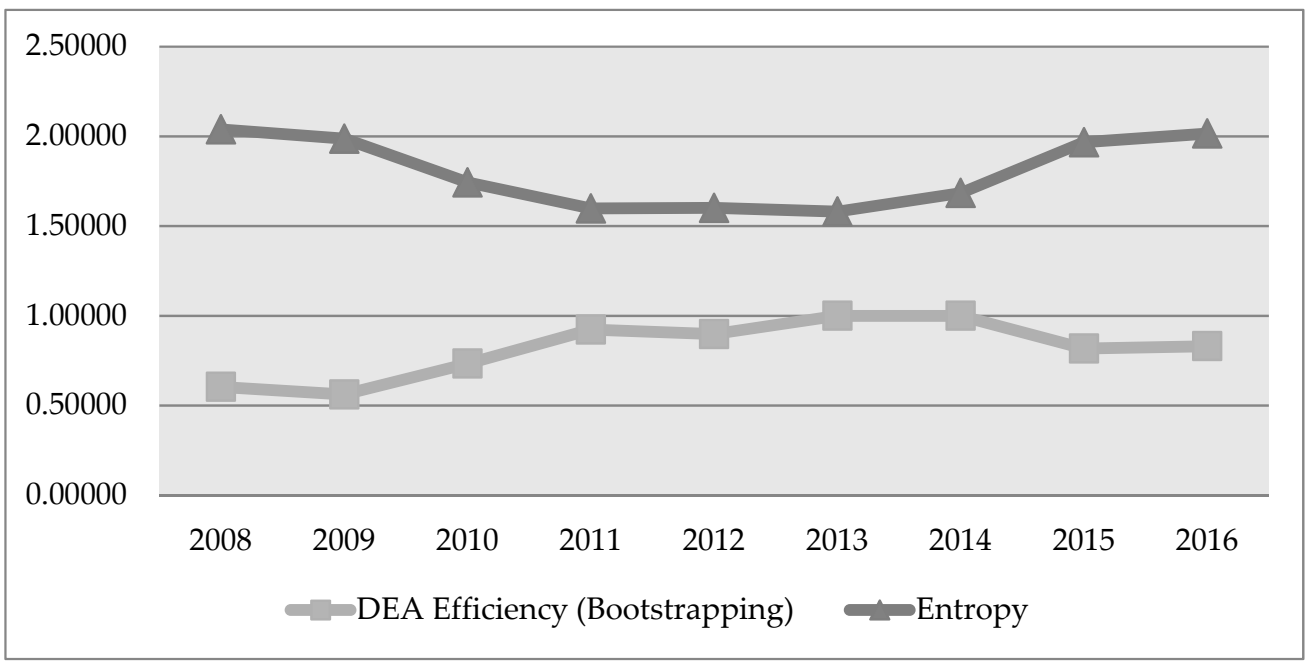

Figure 2. The gambling industry's efficiency and economic diversification in Macao.

Figure 2 show the bootstrapping-DEA efficiency and entropy index of economic diversification from 2008 to 2016. In terms of the gambling industry's efficiency, both the traditional DEA-BCC efficiency and bootstrapping-DEA efficiency of Macao's gambling industry in 2016 were less than 1. Both the DEA-BCC efficiency and bootstrapping-DEA efficiency were 1 in 2013 and 2014. However, the DEA-BCC efficiency and bootstrapping-DEA efficiency showed big differences from 2008 to 2011. Bootstrapping-DEA was less efficient than DEA-BCC from 2008 to 2011. The bootstrapping-DEA efficiency is more efficient because it reduces errors by repeated sampling.

\subsection{Transition Matrix According to Relatedness and Complexity Framework}

Table 3 shows the transition matrix based on the expert interviews. Here are the basic assumed conditions of the Markov chain process: the number of system states in the forecast period remains constant; the system state transition probability matrix will not change over time; and the state transition is only affected by the previous state, namely the non-aftereffect property. A Markov chain is a Markov process with a discrete time and discrete state. In a Markov chain, the transition of system state needs a probability matrix. The probability of a state at any later time point can be forecasted by the probability of states at initial time points through the state transition probability matrix. Thus, this study reaches the transition matrix in Table 3 through interviews with native economic experts and the senior executives of large-scale gambling companies to derive the transition probability matrix of the three scenarios in Table 3, namely, rapid transition from the gambling industry to the non-gambling industry, stable transition from the gambling industry to the non-gambling industry and slow transition from the gambling industry to the non-gambling industry. 
Table 3. Transition probability matrix based on expert interviews.

\begin{tabular}{ccccccc}
\hline & $\begin{array}{c}\text { Scenario 1: Rapid Transition } \\
\text { from the Gambling Industry to } \\
\text { the Non-Gambling Industry } \\
\text { (High Relatedness } \\
\text { Diversification Transition) }\end{array}$ & $\begin{array}{c}\text { Scenario 2: Stable Transition } \\
\text { from the Gambling Industry to } \\
\text { the Non-Gambling Industry }\end{array}$ & $\begin{array}{c}\text { Scenario 3: Slow Transition } \\
\text { from the Gambling Industry to } \\
\text { the Non-Gambling Industry } \\
\text { (Technology-Oriented } \\
\text { Diversification) }\end{array}$ \\
\hline & $\begin{array}{c}\text { Gambling } \\
\text { Industry }\end{array}$ & $\begin{array}{c}\text { Non-Gambling } \\
\text { Industry }\end{array}$ & $\begin{array}{c}\text { Gambling } \\
\text { Industry }\end{array}$ & $\begin{array}{c}\text { Non-Gambling } \\
\text { Industry }\end{array}$ & $\begin{array}{c}\text { Gambling } \\
\text { Industry }\end{array}$ & $\begin{array}{c}\text { Non-Gambling } \\
\text { Industry }\end{array}$ \\
\hline $\begin{array}{c}\text { Gambling } \\
\text { industry }\end{array}$ & $92.0 \%$ & $8.0 \%$ & $95.6 \%$ & $4.4 \%$ & $98.0 \%$ & $2.0 \%$ \\
$\begin{array}{c}\text { Non-gambling } \\
\text { industry }\end{array}$ & $0.5 \%$ & $99.5 \%$ & $0.5 \%$ & $99.5 \%$ & $0.5 \%$ & $99.5 \%$ \\
\hline $\begin{array}{c}\text { Economic } \\
\text { growth rate }\end{array}$ & & & $7 \%$ & & & \\
\hline
\end{tabular}

As shown by the probability results in Table 3 , when the gambling industry stably transfers to the non-gambling industry, in the following year, the probability that the gambling industry transfers to the non-gambling industry is $8 \%$ and the probability that it remains there is $92 \%$; the probability that the non-gambling industry transfers to the gambling industry is $0.5 \%$ and the probability that it remains there is $99.5 \%$.

\subsection{Forecast by the Markov Chain}

This study applies the ring price in 2015 to calculate a total added value (based on the producer's price and one million Macao dollars per unit) of 16 industries in Macao and the proper scales and growth rates of Macao's gambling industry and non-gambling industry were forecast until 2021 through the forecast model of the Markov chain. The situation at the initial time points was that the gambling industry's total output value was much larger than the non-gambling industry's total output value. Table 4 shows the relevant results under the assumption that the gambling industry transfers to the non-gambling industry through a state transition probability matrix.

Table 4. The scales and growth rates for Macao's gambling industry and non-gambling industry forecasted by the Markov chain in three scenarios (unit: million Macao dollars).

\begin{tabular}{|c|c|c|c|c|c|c|c|c|c|c|c|c|}
\hline \multirow[b]{3}{*}{2008} & \multicolumn{4}{|c|}{$\begin{array}{l}\text { Scenario 1: Rapid Transition } \\
\text { from Gambling Industry to } \\
\text { Non-Gambling Industry } \\
\text { (High Relatedness } \\
\text { Diversification Transition) }\end{array}$} & \multicolumn{4}{|c|}{$\begin{array}{l}\text { Scenario 2: Stable Transition } \\
\text { from Gambling Industry to } \\
\text { Non-Gambling Industry }\end{array}$} & \multicolumn{4}{|c|}{$\begin{array}{l}\text { Scenario 3: Slow Transition } \\
\text { from Gambling Industry to } \\
\text { Non-Gambling Industry } \\
\text { (Technology Oriented } \\
\text { Diversification) }\end{array}$} \\
\hline & \multicolumn{2}{|c|}{$\begin{array}{l}\text { Gambling } \\
\text { Industry }\end{array}$} & \multicolumn{2}{|c|}{$\begin{array}{l}\text { Non-Gambling } \\
\text { Industry }\end{array}$} & \multicolumn{2}{|c|}{$\begin{array}{l}\text { Gambling } \\
\text { Industry }\end{array}$} & \multicolumn{2}{|c|}{$\begin{array}{l}\text { Non-Gambling } \\
\text { Industry }\end{array}$} & \multicolumn{2}{|c|}{$\begin{array}{l}\text { Gambling } \\
\text { Industry }\end{array}$} & \multicolumn{2}{|c|}{$\begin{array}{l}\text { Non-Gambling } \\
\text { Industry }\end{array}$} \\
\hline & 105,717 & $\%$ & 141,340 & $\%$ & 105,717 & $\%$ & 141,340 & $\%$ & 105,717 & $\%$ & 141,340 & $\%$ \\
\hline 2009 & 112,708 & 6.6 & 134,009 & -5.2 & 112,708 & 6.6 & 134,009 & -5.2 & 112,708 & 6.6 & 134,009 & -5.2 \\
\hline 2010 & 173,772 & 54.2 & 135,239 & 0.9 & 173,772 & 54.2 & 135,239 & 0.9 & 173,772 & 54.2 & 135,239 & 0.9 \\
\hline 2011 & 231,704 & 33.3 & 145,158 & 7.3 & 231,704 & 33.3 & 145,158 & 7.3 & 231,704 & 33.3 & 145,158 & 7.3 \\
\hline 2012 & 252,773 & 9.1 & 158,832 & 9.4 & 252,773 & 9.1 & 158,832 & 9.4 & 252,773 & 9.1 & 158,832 & 9.4 \\
\hline 2013 & 287,099 & 13.6 & 174,450 & 9.8 & 287,099 & 13.6 & 174,450 & 9.8 & 287,099 & 13.6 & 174,450 & 9.8 \\
\hline 2014 & 265,689 & -7.5 & 186,168 & 6.7 & 265,689 & -7.5 & 186,168 & 6.7 & 265,689 & -7.5 & 186,168 & 6.7 \\
\hline 2015 & 171,105 & -35.6 & 185,085 & -0.6 & 171,105 & -35.6 & 185,085 & -0.6 & 171,105 & -35.6 & 185,085 & -0.6 \\
\hline 2016 & 165,094 & -3.5 & 191,126 & 3.3 & 165,094 & -3.5 & 191,126 & 3.3 & 165,094 & -3.5 & 191,126 & 3.3 \\
\hline 2017 & 163,541 & -0.9 & 217,614 & 13.9 & 169,900 & 2.9 & 211,255 & 10.5 & 174,140 & 5.5 & 207,015 & 8.3 \\
\hline 2018 & 162,154 & -0.8 & 245,682 & 12.9 & 174,925 & 3.0 & 232,911 & 10.3 & 183,711 & 5.5 & 224,125 & 8.3 \\
\hline 2019 & 160,939 & -0.7 & 275,446 & 12.1 & 180,180 & 3.0 & 256,205 & 10.0 & 193,838 & 5.5 & 242,547 & 8.2 \\
\hline 2020 & 159,902 & -0.6 & 307,030 & 11.5 & 185,681 & 3.1 & 281,251 & 9.8 & 204,556 & 5.5 & 262,375 & 8.2 \\
\hline 2021 & 159,050 & -0.5 & 340,567 & 10.9 & 191,441 & 3.1 & 308,176 & 9.6 & 215,902 & 5.6 & 283,715 & 8.1 \\
\hline \multicolumn{13}{|c|}{ Entropy Index of Economic Diversification (2021) } \\
\hline & \multicolumn{4}{|c|}{2.01} & \multicolumn{4}{|c|}{1.84} & \multicolumn{4}{|c|}{1.70} \\
\hline
\end{tabular}


The appropriate scales for Macao's gambling industry and non-gambling industry in 2021 were forecast by the Markov chain. Under scenario 1 referred to Figure 3, the industrial added value of the gambling industry is predicted to be 159.050 billion Macao dollars and the industrial added value of the non-gambling industry is predicted to be 340.567 billion Macao dollars. The growth rates for gambling and non-gambling industry are $-0.5 \%$ and $10.9 \%$ respectively. The economic diversification entropy index is predicted to be 2.01 .

Under scenario 2 referred to Figure 4, the gambling industry moves smoothly to the non-gambling industry. In 2021, the industrial added value of Macao's gambling industry is predicted to be 191.441 billion Macao dollars, the industrial added value of the non-gambling industry is predicted to be 308.176 billion Macao dollars, the growth rates for gambling and non-gambling industry are $3.1 \%$ and $9.6 \%$ respectively and the economic diversification entropy index is predicted to be 1.84 .

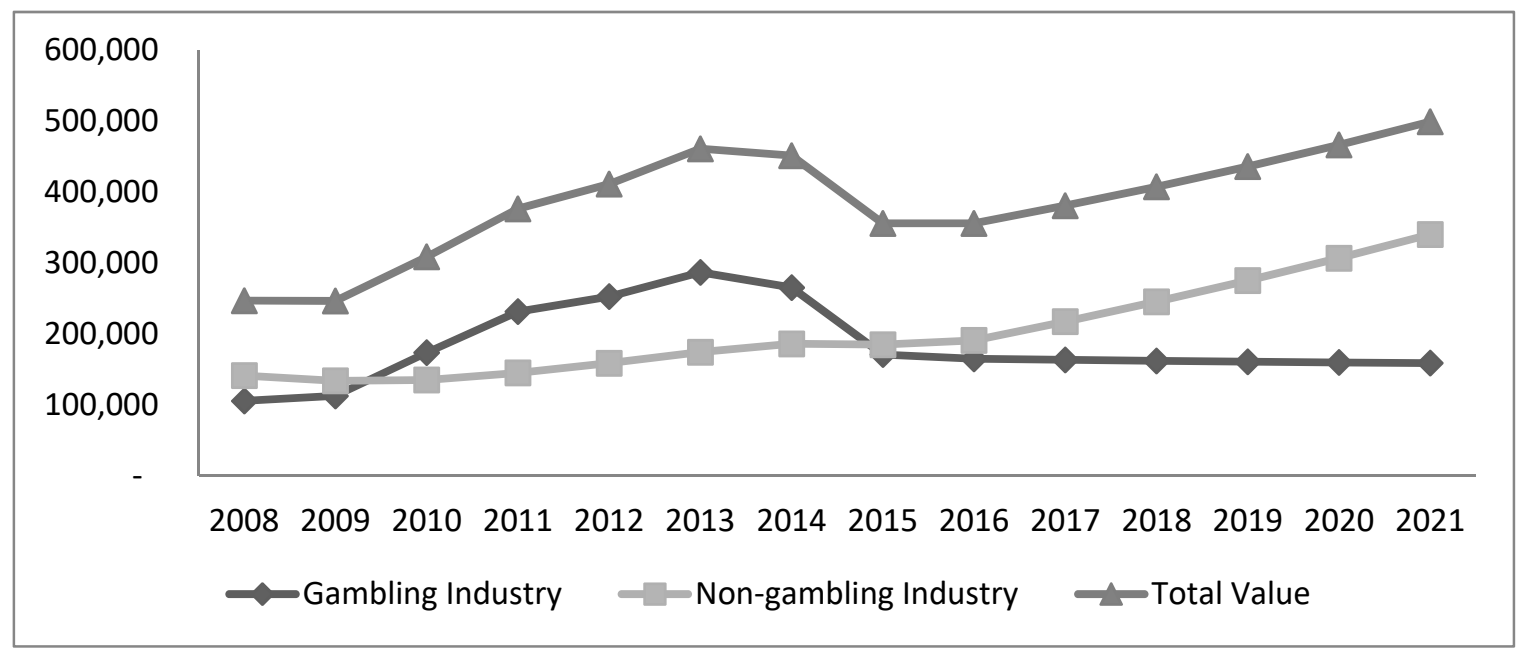

Figure 3. The scale for Macao's gambling industry forecast by the Markov chain—scenario 1.

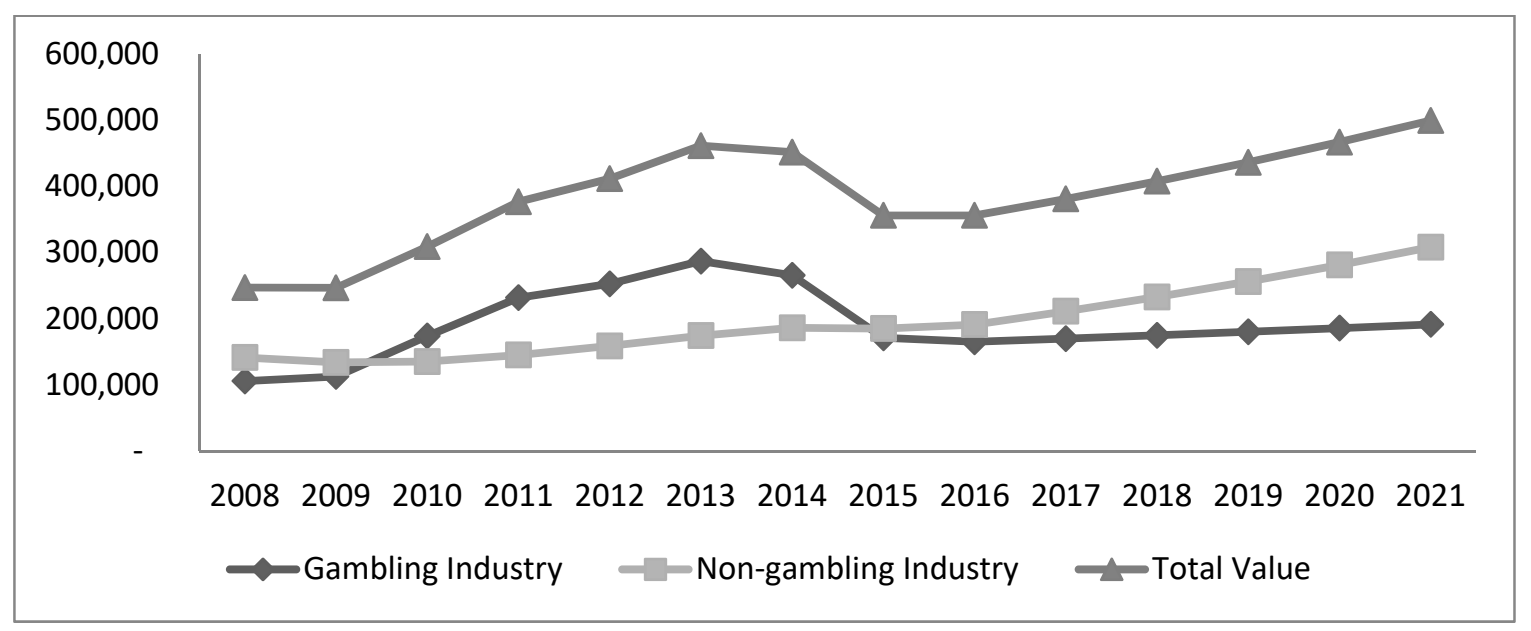

Figure 4. The scale of Macao's gambling industry forecast by the Markov chain—scenario 2.

Under scenario 3 referred to Figure 5, the gambling industry slowly moves to the non-gambling industry. In 2021, the industrial added value of the Macao's gambling industry is predicted to be 215.902 billion Macao dollars and the industry added value of the non-gambling industry is predicted to be 283.715 billion Macao dollars. The growth rates for gambling and non-gambling industry are $5.6 \%$ and $8.1 \%$ respectively. The economic diversification entropy index is predicted to be 1.70 . Under the three scenarios, the overall added value of Macao is continuously increasing. 


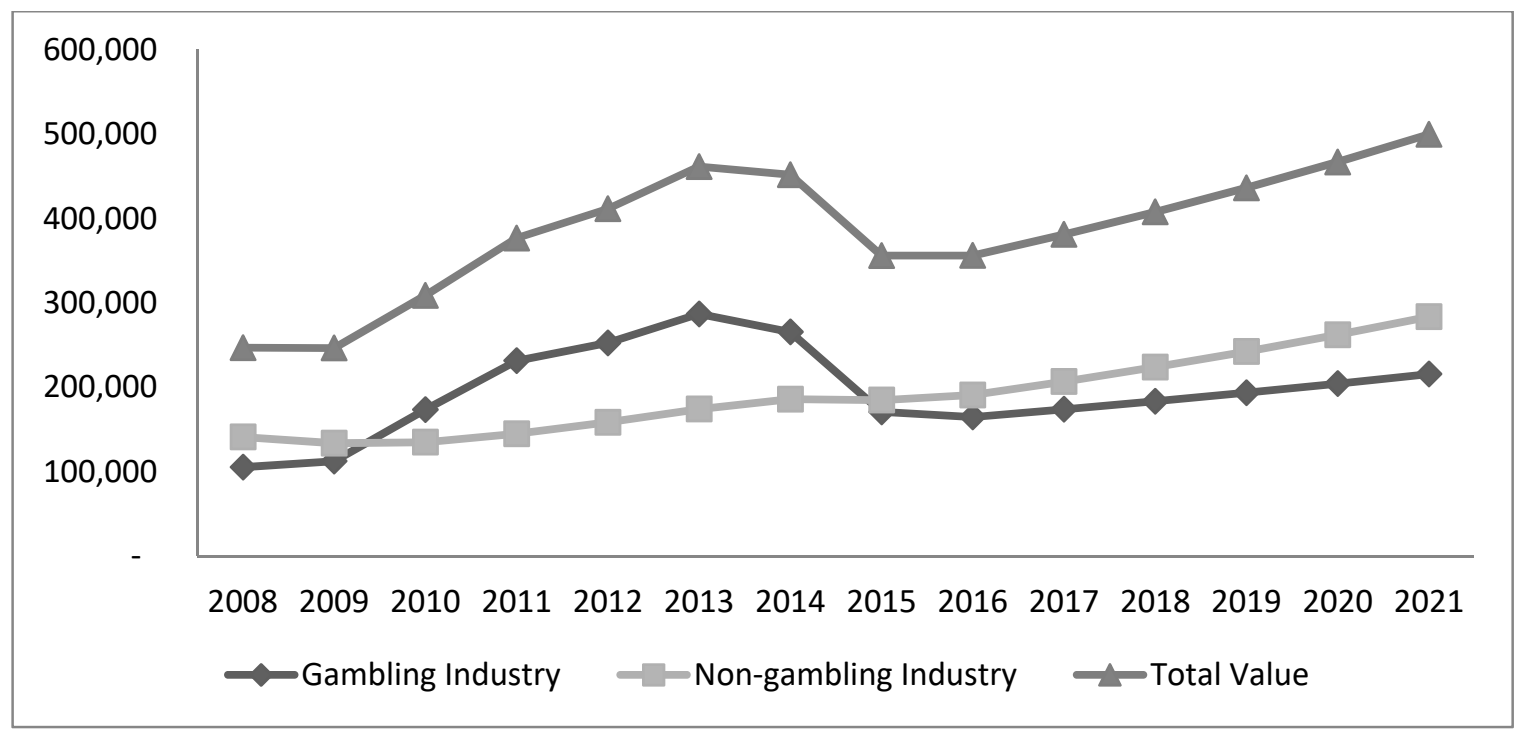

Figure 5. The appropriate scale of Macao's gambling industry forecasted by the Markov chain—scenario 3.

\section{Discussion}

The entropy index of economic diversification in Macao, which was calculated in Section 4.1, was 1.99 in 2009. According to Measuring Economic Diversification in Hawaii [17] published by the Department of Business, Economic Development and Tourism of Hawaii in 2011, the entropy index of economic diversification of Hawaii, which positions tourism as its pillar industry, was 2.61 in 2009, while the value of the same index in the state of Nevada, home to Las Vegas, which positions gambling as its pillar industry, was 2.64. Both of these relevant index values are higher than Macao's, which means their level of economic diversification is higher than Macao's. From the empirical calculation of the entropy index of economic diversification and the comparison to Hawaii and Nevada, which have mainstay industries of gambling and tourism, respectively, Macao is revealed to have a relatively high industrial concentration and insufficient industrial diversification.

The calculation of efficiency by bootstrapping-DEA based on VRS is more accurate than efficiency calculated by the traditional BCC-VRS model, because the traditional DEA method has an advantage in parameter estimation. However, the traditional DEA method may bias the sample evaluation so that the statistic test is ignored. A bootstrapping-DEA model can make up for the traditional DEA method's deficiency by simulating the process of data generation through repeated sampling to fix the bias in the sample evaluation results. This study shows that the bootstrapping-DEA efficiency computed by repeated sampling calculation is more accurate than the efficiency computed by the traditional BCC-VRS model. Bootstrapping-DEA takes statistical tests into consideration so that bias resulting from sample evaluation is avoided.

This result is consistent with actual observations. During the gambling industry depression that began in 2015, the central government of China had adjusted the number of visitors to Macao, which resulted in the decline of gambling tax revenue. When gambling tax revenue declined, the level of Macao's economic diversification improved to some degree. Therefore, it is necessary to transfer the gambling industry's added value to the non-gambling industry.

\section{Conclusions}

\subsection{Summary and Implications}

The principle of determining an appropriate scale for Macao's gambling industry is based on the premise of achieving appropriate diversification in Macao's economy. The gambling industry is the dominant industry in Macao. The goal of achieving appropriate industrial diversification in 
Macao is associated with issues about scale and efficiency in the gambling industry. Therefore, we need to calculate the efficiency of the gambling industry by a bootstrapping-DEA model based on VRS. In terms of the gambling industry's efficiency, in 2016, both the traditional DEA-BCC efficiency and the bootstrapping-DEA efficiency of the gambling industry were less than 1 , which reveals insufficient efficiency in the operation of the gambling industry. In 2013 and 2014, both the DEA-BCC efficiency and the bootstrapping-DEA efficiency were 1, which means Macao's gambling industry was efficient in these two years. However, the DEA-BCC efficiency and bootstrapping-DEA efficiency showed big differences from 2008 to 2011.

Through the Markov chain forecast, the quantitative gambling industry scale for the goal of appropriate economic diversification can be given. The appropriate scales for Macao gambling industry and non-gambling industry in 2021 were forecast by a Markov chain. Under the three scenarios, the overall added value of Macao was predicted to continuously increase. Under scenario 1, although the entropy index of economic diversification is high and the growth rate for non-gambling industry is above $10 \%$, the growth rate for gambling industry is negative. Therefore, rapid transition causes an issue of sustainable growth for the gambling industry. Under scenario 3 , when the growth rate of gambling is around $5.5 \%$, the growth rate of non-gambling is around $8.2 \%$. This growth rate is lower than the growth rates in 2012 and 2013. The slow transition does not provide a satisfying economic diversification. Under scenario 2, the gambling industry is smoothly transferred to the non-gambling industry. In 2021, in case the growth rate of gambling is around $3 \%$, an economic diversification entropy index of 1.84 will be more suitable for the actual situation that the growth rate for non-gambling industry is around $10 \%$.

\subsection{Theoretical Contributions}

The results of this study make the following three theoretical contributions. First, according to the Chicago School of Industrial Economics Theory, the larger the scale of an industry, the higher its efficiency and innovation ability [50] but the sustainable development theory puts limits the growth. Macao is a small economy. The gambling industry dominates more than half of the whole economy. It has negative externalities, so it is easily affected by the external environment and has a siphon effect on other industries. Therefore, the continuous expansion of the gambling industry is unsustainable for the industry itself and the overall economy and society. Macao and some other international cities that position gambling and tourism as a pillar industry has always advocated for moderate diversification of the industry. Therefore, this study discusses how to assess the achievement of a moderately diverse economy in a small economy and how to obtain quantitative and appropriate scales to achieve economically sustainable development in the small economy.

Second, this study confirms that the scale of the current gambling industry in Macao is in line with the theory of congestion of production factors, which states that overdevelopment of a dominant industry will reduce its own efficiency and harm the development of other industries [51]. In recent years, the scale of the gambling industry has expanded and its efficiency has declined. This study shows that controlling the gambling industry in an appropriate scale can improve its efficiency. This study also shows that a stable transition from gambling industry to non-gambling industry can achieve a moderate economic diversification.

Finally, Macao needs to have sustainably economic diversification including the sustainable development of the gambling industry. Economic diversification aims to speed up the growth of economic outputs from a range of industries. It leads to a consequence of long-term economic growth which provides economic well-being in much longer-term through the notion of economic sustainability. For having economic sustainability, economic diversification is not just the economic development of certain industries. It involves technical and institutional arrangements by which output is produced and distributed [52]. Thus, we need to determine how to influence the other industries under the premise of sustainable development of the gambling industry. To develop a robust and stable economy, Macao's gambling industry should appropriately adjust its scale and 
diversify as much as possible to adjust to the development status that is most suitable to achieve sustainable development and the continued development of other industries. This study contributes to sustainability study a model that can be used to reveal the optimal level of development of gaming industry in order to create conditions for economic diversification in Macao. This model can also be used to calculate the appropriate scale for one industry to optimally develop economic diversification in other cities.

\subsection{Practical Implications}

With regard to the sustainable development of the gambling industry, continuous expansion of the scale of the gambling industry cannot result in sustainable high efficiency. The gambling industry experienced more production costs in 2016 and its scale in 2016 was larger than its scale in 2013 or 2014, while its efficiency in 2016 was lower than its efficiency in 2013 or 2014, which means that there was a waste of resources. Thus, government officials and casino operators should pay more attention to the improvement of the gambling industry's efficiency. For instance, the number of gambling tables in Macao was 5700-5800 in 2013 and 2014 and 6287 in 2016 but the efficiency in 2016 was not as high as in 2013 and 2014. There was a waste of resources. The casino operators should put more efforts to increase their efficiency and not just look for enlarging their market shares. For example, the casino operators could combine gambling with other cultural and entertainment industries to increase the overall efficiency.

In terms of policy about the gambling industry's sustainable development, from 2016 to 2017, the Macao SAR government first proposed a specific indicator that the growth rate of total number of gambling tables in the ten years after 2013 should be no more than 3\% and that the addition of new gambling tables should be strictly regulated to adjust the gambling's industry scale. However, this study has found that this policy failed to achieve the goal of regulating Macao's gambling industry scale to make the industry appropriately diversified. This study reveals a new understanding that there must be a significant transition of the gambling industry economy to the non-gambling industry economy to achieve a moderately diversified economy. The local government should consider imposing certain requirements facilitating economic diversification when issuing casino licenses in the coming years.

According to the results of this study, under Scenario 2, for the gambling industry to move smoothly to non-gambling industries, the Macao government should slash the added value of the gambling industry and increase the added value from non-gambling industries. In addition to developing industries related to gambling and tourism for diversifying tourists' consumption options [53], it is necessary to develop a platform for innovation and technology development. However, given Macao has a land area of just $30.8 \mathrm{~km}^{2}$, with much of the land being occupied by gambling operators [54], where and how to develop the platform for diversifying its economic structure will be a challenge for the Macao government.

\subsection{Limitation and Further Studies}

This study has some limitations. First, although a transition matrix forecast by a Markov chain was specified by this study, the relevant probability of the transition matrix needs further research, for example, through interviews with experts from neighboring areas or by conducting a questionnaire survey. In addition, more diversified input indicators, for example, the number of slot machines and casino acreage, could be added into the bootstrapping-DEA model as variables. Last, future research needs to pay more attention to the methods and policies of increasing the non-gambling industry's added value.

In a small economy like Macao, the gambling industry dominates the whole economy. The gambling industry alone occupies more than $50 \%$ of Macao GDP on average. Therefore, the degree of diversity is high only when the income of the gambling industry is reduced. This is because the income of the gambling industry is highly related to the index of diversity. However, 
the efficiency of gambling industry is calculated from its input-output. So, the index of diversity cannot be used to determine the relationship between the efficiency of the gambling industry and diversification. The future study is recommended to evaluate any relationship between the input of gambling industry and the diversity of the overall economy.

Author Contributions: F.C. initially conceived and designed the research. She performed the data analysis and original draft preparation under the supervision of the corresponding authors. C.T.H. provided suggestions for the data analysis. Y.H.M., a corresponding author, developed the original idea of this study and supervised the research project. I.K.W.L., a corresponding author, wrote the manuscript and provided quality assurance.

Funding: This research was funded by the key project grant of National Natural Science Foundation of China PRC, "The Establishment of Linkage Mechanism Serving for The Belt and Road Initiative and Development Research of Guangdong, Hong Kong and Macao". (Grant No. U1601218) and the major project grant of the National Social Science Fund of China PRC, "Research on the Coordination Development Mechanism and System of the Guangdong-Hong Kong-Macao Greater Bay Area in the New Era." (Grant No.:18ZDA041).

Acknowledgments: The authors are thankful to Jian Xin Rong and Post-doc. Jin Wei Liang for their valuable comment and helpful suggestions. They are core members of the research team of Yanhua Mao.

Conflicts of Interest: The authors declare no conflict of interest.

\section{References}

1. Yearbook of Statistics 2017. Available online: https://www.dsec.gov.mo/Statistic.aspx?lang=en-US\& NodeGuid=d45bf8ce-2b35-45d9-ab3a-ed645e8af4bb (accessed on 1 January 2019).

2. Hua, Y.M. Macao moderate economic diversification: Connotation, path and policy. J. Sun Yat-Sen Univ. Soc. Sci. Ed. 2009, 49, 149-157. (In Chinese)

3. Gu, X.; Li, G.; Chang, X.; Guo, H. Casino tourism, economic inequality, and housing bubbles. Tour. Manag. 2017, 62, 253-263. [CrossRef]

4. Hackbart, M.M.; Anderson, D.A. On measuring economic diversification. Land Econ. 1975, 51, $374-378$. [CrossRef]

5. Abouchakra, R.; Shediac, R.; Moujaes, C.N.; Najjar, M.R. Economic Diversification: The Road to Sustainable Development; Booz \& Company: New York, NY, USA, 2008.

6. Nourse, H.O. Regional Economics: A Study in the Economic Structure, Stability and Growth of Regions; McGraw-Hill: New York, NY, USA, 1968.

7. Government of the Macao Special Administrative Region. 2018 Policy Address. Available online: https:/ / images.io.gov.mo/cn/lag/lag2018_cn.pdf (accessed on 1 January 2019). (In Chinese)

8. Government of the Macao Special Administrative Region. Yearbook of Statistics 2018. Available online: https: / / www.dsec.gov.mo/Statistic.aspx?NodeGuid=d45bf8ce-2b35-45d9-ab3a-ed645e8af4bb (accessed on 1 January 2019).

9. Government of the Macao Special Administrative Region. Policy Address for the Fiscal Year 2019. Available online: https: / www.policyaddress.gov.mo/policy/home.php?lang=en (accessed on 1 January 2019).

10. San, C.S. Rationales and options for economic diversification in Macao; Monetary Authority of Macao: Macau, China, 2006.

11. Greenwood, V.A.; Dwyer, L. Reinventing Macau tourism: Gambling on creativity? Curr. Issues Tour. 2017, 20, 580-602. [CrossRef]

12. Wan, Y.K.P.; Li, X. Sustainability of tourism development in Macao, China. Int. J. Tour. Res. 2013, 15, 52-65. [CrossRef]

13. Xi, L.; Wei, C.S. The way to the diversification of Macau's social economy: A study on Macau's cultural tourism development. Int. J. Tradeeconomics Financ. 2010, 1, 131. [CrossRef]

14. Zhang, Y.; Kwan, F. Macao's gaming-led prosperity and prospects for economic diversification. China Int. J. 2009, 7, 288-319. [CrossRef]

15. Hvidt, M. Economic Diversification in GCC Countries: Past Record and Future Trends; The London School of Economics and Political Science: London, UK, 2013.

16. UNFCCC. The Concept of Economic Diversification in the Context of Response Measures Technical Paper by the Secretariat. 6 May 2016. Available online: https://unfccc.int/resource/docs/2016/tp/03.pdf (accessed on 1 January 2019). 
17. Liu, M.T.; Chang, T.T.G.; Loi, E.H.; Chan, A.C.H. Macau gambling industry: Current challenges and opportunities next decade. Asia Pac. J. Mark. Logist. 2015, 27, 499-512. [CrossRef]

18. Lu, P. Study on the Moderate Diversification of Industrial Structure in Macao. Am. J. Ind. Bus. Manag. 2016, 6, 176. [CrossRef]

19. Wei, D. Research on Industrial Development Strategy of Macao. J. Tsinghua Univ. Philos. Soc. Sci. Ed. 2000, 15, 43-51. (In Chinese)

20. Harrison, B.; Kelley, M.R.; Gant, J. Innovative firm behavior and local milieu: Exploring the intersection of agglomeration, firm effects, and technological change. Econ. Geogr. 1996, 72, 233-258. [CrossRef]

21. Porter, M.E. Location, competition, and economic development: Local clusters in a global economy. Econ. Dev. Q. 2000, 14, 15-34. [CrossRef]

22. Delgado, M.; Porter, M.E.; Stern, S. Clusters, convergence, and economic performance. Res. Policy 2014, 43, 1785-1799. [CrossRef]

23. Aratuo, D.N.; Etienne, X.L. Industry level analysis of tourism-economic growth in the United States. Tour. Manag. 2019, 70, 333-340. [CrossRef]

24. Rosenthal, S.S.; Strange, W.C. Evidence on the nature and sources of agglomeration economies. In Handbook of Regional and Urban Economics; Elsevier: Amsterdam, The Netherlands, 2004; pp. 2119-2171.

25. Kolko, J. Urbanization, agglomeration, and coagglomeration of service industries. In Agglomeration Economics; University of Chicago Press: Chicago, IL, USA, 2010; pp. 151-180.

26. Smith, A. An Inquiry into the Nature and Causes of the Wealth of Nations; Thomas Nelson and Sons: Edinburgh, UK, 1887; Volume 2.

27. Marshall, A. Principles of Economics: An Introductory Volume; Macmillan: London, UK, 1961.

28. Raj, S.K. Measuring Economic Diversification in Hawaii. Research and Economic Analysis Division (READ), Department of Business, Economic Development and Tourism of Hawaii, 2008. Available online: http:/ / files.hawaii.gov/dbedt/economic/data_reports/EconDiversification/Economic_ Diversification_Report_Final\%203-7-08.pdf (accessed on 1 January 2019).

29. Banker, R.D.; Charnes, A.; Cooper, W.W. Some models for estimating technical and scale inefficiencies in data envelopment analysis. Manag. Sci. 1984, 30, 1078-1092. [CrossRef]

30. Seiford, L.M.; Thrall, R.M. Recent developments in DEA: The mathematical programming approach to frontier analysis. J. Econom. 1990, 46, 7-38. [CrossRef]

31. Banker, R.D.; Thrall, R.M. Estimation of returns to scale using data envelopment analysis. Eur. J. Oper. Res. 1992, 62, 74-84. [CrossRef]

32. Gilks, W.R.; Richardson, S.; Spiegelhalter, D. Markov Chain Monte Carlo in Practice; Chapman and Hall/CRC: London, UK, 1995.

33. Kort, J.R. Regional economic instability and industrial diversification in the US. Land Econ. 1981, 57, 596-608. [CrossRef]

34. Conroy, M.E. The concept and measurement of regional industrial diversification. South. Econ. J. 1975, 41, 492-505. [CrossRef]

35. Tress, R.C. Unemployment and the Diversification of Industry 1. Manch. Sch. 1938, 9, 140-152. [CrossRef]

36. Tim, C.; Reda, C.; Fuad, H.; Amgad, H.; Padamha, K. Economic Diversification in the GCC: Past, Present, and Future; International Monetary Fund: Washington, DC, USA, 2014.

37. UNESCAP. Economic Diversification in Asian Landlocked Developing Countries: Prospect and Challenges; 2014. Available online: https:/ / www.unescap.org/sites/default/files/Economic\%20Diversification_low\% 20resolution.pdf (accessed on 15 March 2019).

38. Li, K.X.; Jin, M.; Shi, W. Tourism as an important impetus to promoting economic growth: A critical review. Tour. Manag. Perspect. 2018, 26, 135-142. [CrossRef]

39. Wu, S.T.; Chen, Y.S. The social, economic, and environmental impacts of casino gambling on the residents of Macau and Singapore. Tour. Manag. 2015, 48, 285-298. [CrossRef]

40. Li, G.; Gu, X.; Siu, R.C.S. The impacts of gaming expansion on economic growth: A theoretical reconsideration. J. Gambl. Stud. 2010, 26, 269-285. [CrossRef] [PubMed]

41. Wan, Y.K.P. The social, economic and environmental impacts of casino gaming in Macao: The community leader perspective. J. Sustain. Tour. 2012, 20, 737-755. [CrossRef] 
42. Ivan, K.W.L.; Michael, H.; Dong, L.; Yedi, L. The influence of word of mouth on tourism destination choice: Tourist-resident relationship and safety perception among Mainland Chinese tourists visiting Macau. Sustainability 2018, 10, 2114.

43. Glaeser, E.L. Introduction to "Agglomeration Economics". In Agglomeration Economics; University of Chicago Press: Chicago, IL, USA, 2010; pp. 1-14.

44. Marshall, A. Principles of Economics, 9th ed.; Macmillan: London, UK, 1920.

45. Glaeser, E.L.; Gottlieb, J.D. The wealth of cities: Agglomeration economies and spatial equilibrium in the United States. J. Econ. Lit. 2009, 47, 983-1028. [CrossRef]

46. Simar, L.; Wilson, P.W. Sensitivity analysis of efficiency scores: How to bootstrap in nonparametric frontier models. Manag. Sci. 1998, 44, 49-61. [CrossRef]

47. Charnes, A.; Cooper, W.W.; Rhodes, E. Measuring the efficiency of decision making units. Eur. J. Oper. Res. 1978, 2, 429-444. [CrossRef]

48. Zhang, Z. Changes in the market structure of the gaming industry and in performance of Macao. Greater Pearl River Delta Forum 2008, 1, 1-12. (In Chinese)

49. Zhangping, Y. Research on the Appropriate Scale of Gaming Industry and Diversification of Industrial Structure: Taking Macao as an Example; Social Science Literature Publishing House: Beijing, China, 2017. (In Chinese)

50. Stigler, G.J. The Organization of Industry; University of Chicago Press: Chicago, IL, USA, 1983.

51. Kaya, A.; Koc, M. Over-Agglomeration and Its Effects on Sustainable Development: A Case Study on Istanbul. Sustainability 2019, 11, 135. [CrossRef]

52. Herrick, B.; Kindleberger, C.P. Economic Development, 4th ed.; McGraw-Hill: Singapore, 1983.

53. Jingwen, W.; Liang, M.Z. Characteristics of visitor expenditure in Macao and their impact on its economic growth. Tour. Econ. 2018, 24, 218-233. [CrossRef]

54. Sheng, M.; Gu, C. Economic growth and development in Macau (1999-2016): The role of the booming gaming industry. Cities 2018, 75, 72-80. [CrossRef]

(C) 2019 by the authors. Licensee MDPI, Basel, Switzerland. This article is an open access article distributed under the terms and conditions of the Creative Commons Attribution (CC BY) license (http:/ / creativecommons.org/licenses/by/4.0/). 